Journal of Science
http://dergipark.gov.tr/gujs

\title{
Evaluation of Arsenic Concentration in Poultry and Calf Meat Samples by Hydride Generation Atomic Fluorescence Spectrometry
}

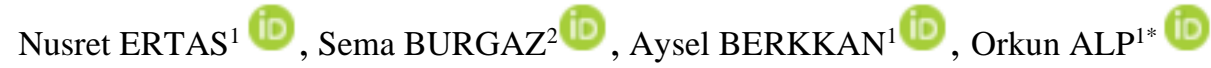 \\ ${ }^{I}$ Gazi University, Faculty of Pharmacy, Analytical Chemistry Department, 06330 Ankara, TURKEY \\ ${ }^{2}$ Gazi University, Faculty of Pharmacy, Toxicology Department, 06330 Ankara, TURKEY
}

\begin{tabular}{l} 
Highlights \\
\hline - Determination of ars \\
- Arsenic concentration \\
- Daily intake of total \\
Article Info \\
\hline Received: 08 July 2020 \\
Accepted: 30 Nov 2020 \\
Keywords \\
Arsenic \\
Hydride generation \\
Atomic fluorescence \\
spectrometry \\
Poultry \\
Calf
\end{tabular}

\section{INTRODUCTION}

Heavy metals are toxic substances for living organisms and with the influence of industrialization, the risk of heavy metal exposure for humans' increases rapidly. Amongst the heavy metals, arsenic naturally occurs in the environment, especially in water and soil [1]. Thus, human exposure to arsenic generally occurs via consuming drinking water and foods. It is a well-known fact that arsenic is toxic to humans and arsenic toxicity is related with its chemical form and organic arsenicals are less toxic than inorganic arsenic (i-As) species [2]. In addition, oxidation state is an important parameter since toxicity depends on the oxidation state of arsenic which +3 oxidation state arsenicals are more toxic than +5 oxidation state arsenicals.

The absorption of inorganic arsenic species takes place via the gastrointestinal path, and the metabolism of i-As species occurs through methylation. Methylated arsenicals such as monomethylarsonic acid (MMA) and dimethylarsinic acid (DMA) are formed as the result of methylation process [3]. In 2014, European Food Safety Authority (EFSA) evaluated dietary exposure to i-As and a benchmark dose level (BMDL): $0.3-8 \mu \mathrm{g} / \mathrm{kg}$ body weight per day was designated for an increased risk of various types of cancer as well as for skin lesions $[4,5]$. Under these circumstances, to determine arsenic at ppb or sub ppb concentration is important in consumer products, especially in food products. Roxarsone (ROX) which is a phenylarsenic compound, had been used in poultry production in a widespread manner as a feed additive, for the purpose of preventing diseases and increasing weight gain [6]. ROX is a compound that has low toxicity; however, 
the studies showed that its continuous usage could lead toxicity since it is transformed into i-As in chicken tissues $[7,8]$.

The atomic techniques such as inductively coupled plasma mass spectrometry (ICP-MS) [9-15], hydride generation atomic absorption spectrometry (HG-AAS) [16-21] and hydride generation atomic fluorescence spectrometry (HG-AFS) [22-25] are widely used to determine arsenic in various samples. It is well known that the use of HG can improve the sensitivity and the selectivity in arsenic determination. In addition, atomic techniques coupled with HG allow either total arsenic determination or speciation of arsenic species. Amongst the atomic techniques, the sensitivity of HG-AFS is similar to ICP-MS and better than HG-AAS. Also, simplicity and low operational costs of HG-AFS compared to ICP-MS results in widespread usage of this technique for arsenic determination at trace levels. The drawback of ICP-MS is the polyatomic interferences due to matrix components of the sample. Conversely, hydride forming analytes such as arsenic, selectively separated from matrix components during hydride generation step, as a consequence interferences related to matrix components are avoided at HG-AFS technique. On the other hand, arsenic speciation analysis can be achieved by coupling high performance liquid chromatography (HPLC). In a recent study, Saucedo-Velez et al. [26] used microwave assisted extraction method and determined phenyl arsenicals in feed samples by HPLC-HG-AFS. According to their results, only $p$-arsanilic acid (0.72 - 12.91 $\mathrm{mg} / \mathrm{kg}$ ) was determined among the analyzed arsenic species in feed samples. Nachman et al. compared iAs concentrations in various chicken samples and emphasized that conventional chicken samples had higher arsenic concentrations than the other samples. Also according to their results, ROX concentrations decreased and i-As concentrations increased when the samples were cooked which showed that the cooking process had influence on arsenic forms [27, 28]. Hu et al. used HPLC-ICP-MS for speciation analysis of inorganic and organic arsenic species in chicken meat and both roxarsone and inorganic arsenic were detected at notably high amounts in chicken samples [29]. In an another study, cigarette filter was utilized as an adsorbent and coupled with HG-AFS for determination of total arsenic in various food samples such as vegetables, rice, chicken and fish [20]. The limit of detection (LOD) of the method in food samples was differed in the range of 2.5 to $9.9 \mathrm{ng} / \mathrm{g}$. Perello et al. examined the influence of cooking processes on the concentration of arsenic by using ICP-MS and according to the results, As concentration in meat samples decreased after cooking processes while the concentration of As in chicken samples does not differ [30].

In this study it was aimed to determine total arsenic concentrations in poultry and calf meat samples obtained from commercial markets in Turkey. With this purpose, cost effective and an easy analytical procedure based on HG-AFS was used. In addition, the amount of total arsenic intake from consumption of meat products was estimated.

\section{MATERIAL METHOD}

\subsection{Instrumentation}

Millennium Excalibur atomic fluorescence spectrometer coupled with continuous flow hydride generation system (PS Analytical Ltd., United Kingdom) was used for arsenic determination. An arsenic boosteddischarge hollow cathode lamp was used and the fluorescence signal intensity of As was measured at 193.7 nm.

\subsection{Reagents and Materials}

Unless otherwise stated, ultra pure water was used for the preparation of the solutions. All the chemicals used throughout the experiments were of analytical reagent grade. Arsenic species in the samples were oxidized to arsenic (V) during the digestion step therefore, calibration standards $(0,25,50,100,250,500$, $1000 \mathrm{pg} / \mathrm{mL}$ ) were prepared from $1000 \mathrm{mg} / \mathrm{L}$ As (V) standard (CertiPUR Merck, Germany) daily by appropriate dilutions. As a consequence, the hydride generation efficiency of the samples and calibration standards were identical. The final concentration of $\mathrm{HCl}$ (Merck) and $\mathrm{H}_{2} \mathrm{SO}_{4}$ (Merck) in calibration standards were $1.5 \mathrm{~mol} / \mathrm{L}$ and $0.45 \mathrm{~mol} / \mathrm{L}$, respectively so that final acid concentrations in the samples and the calibration standards did not differ. The reducing reagent $\mathrm{NaBH}_{4}$ (min. 96\% purity, Aldrich) was prepared in $0.4 \%(\mathrm{~m} / \mathrm{v}) \mathrm{NaOH}$ (Aldirch) for hydride generation. The validation of the method was performed by using certified reference material (CRM) DOLT 3 Dogfish Liver (NRC, Canada). In order to 
transport generated arsenic hydrides from gas-liquid separator to the atomizer argon (Ar, high-purity grade) was used as carrier gas and to avoid moisture accumulation nitrogen $\left(\mathrm{N}_{2}\right)$ was used as dryer gas at HG-AFS instrument.

\subsection{Determination of Arsenic by HG-AFS}

The oxidation state of arsenic affect the sensitivity because the hydride generation efficiency of arsenic species are different from each other and the sensitivity of As (III) is higher than As (V). Therefore, in order to achieve lower LOD values, As (III) is more convenient than As (V). Nevertheless, when calibration standards were prepared from As (V) the sensitivity was still sufficient to determine arsenic at trace level in meat samples. Thus, the samples were analyzed without using a pre-reduction step and the sample preparation step was simplified.

Arsenic hydride was generated with continuous flow hydride generation manifold by using $\mathrm{NaBH}_{4}$ at a concentration of $1.4 \%(\mathrm{~m} / \mathrm{v})$ as a reducing agent and $1.5 \mathrm{~mol} / \mathrm{L} \mathrm{HCl}$ as a carrier solution. The sample, carrier and reducing solutions were pumped $(4.0 \mathrm{~mL} / \mathrm{min})$ simultaneously into the sample valve for mixing. Depending on the valve position, whether sample or carrier solution was mixed with $\mathrm{NaBH}_{4}$ via using a PTFE tubing $\left(0.8 \mathrm{~mm}\right.$ i.d., $20 \mathrm{~cm}$ in length) and the other goes off to waste. After mixing with $\mathrm{NaBH}_{4}$, gaseous and liquid phases were separated at gas-liquid separator, where the generated arsenic hydride was transferred to the diffusion flame atomizer $\left(\mathrm{H}_{2}-\mathrm{Ar}\right)$. The peak area of fluorescence signal was used for quantification and the optimized parameters for HG-AFS system are summarized in Table 1. The quantification of arsenic concentration in meat samples was achieved with aqueous calibration standards.

Table 1. HG-AFS method parameters

\begin{tabular}{ll}
\hline Hydride generation & \\
\hline $\mathrm{NaBH}_{4}$ concentration, $\mathrm{m} / \mathrm{v}$ & $1.4 \%$ in $0.4 \% \mathrm{NaOH}$ \\
$\mathrm{HCl}$ concentration, $\mathrm{mol} / \mathrm{L}$ & 1.5 \\
Solution flow rate, $\mathrm{mL} / \mathrm{min}$ & 4.0 \\
Mixing coil length, $\mathrm{cm}$ & 20 \\
\hline Atomic fluorescence spectrometer & \\
\hline Carrier gas flow rate, $\mathrm{L} / \mathrm{min}$ & 0.25 \\
Dryer gas flow rate, $\mathrm{L} / \mathrm{min}$ & 2.5 \\
Wavelength, nm & 193.7 \\
Acquisition time, $\mathrm{s}$ & 30 \\
Signal integration & Peak area \\
\hline
\end{tabular}

\section{RESULTS AND DISCUSSION}

\subsection{Optimization of Acid Concentrations and Sample Amount for Open Vessel Digestion}

Digestion of samples was achieved by slight modification of the open vessel digestion procedure which was proposed by Welz et al. [31]. Before digesting the poultry and calf meat samples, DOLT 3 CRM was used in order to find out the optimum acid volumes for digestion procedure. Thus, to achieve complete digestion, volume of concentrated $\mathrm{HNO}_{3}$ and $\mathrm{HClO}_{4}$ was varied between $2.0-5.0 \mathrm{~mL}$ and $0.5-1.5 \mathrm{~mL}$, respectively. As shown in Figure 1 the volume of $\mathrm{HNO}_{3}$ is more important than $\mathrm{HClO}_{4}$ volume for digestion of the samples. Also at least $3.0 \mathrm{~mL}$ of concentrated $\mathrm{HNO}_{3}$ is needed for complete digestion. However, when $3.0 \mathrm{~mL} \mathrm{HNO}_{3}$ was used for digestion, the accuracy of the digestion was appropriate but the precision was not proper. Therefore, $4.0 \mathrm{~mL} \mathrm{HNO}_{3}$ was used throughout the experiments. The effect of $\mathrm{HClO}_{4}$ was significant when $\mathrm{HNO}_{3}$ was used less than $3.0 \mathrm{~mL}$, but when $\mathrm{HNO}_{3}$ was used either 4.0 or $5.0 \mathrm{~mL}$ the effect of $\mathrm{HClO}_{4}$ volume was insignificant, only the standard deviation values were improved. Thus, $1.0 \mathrm{~mL} \mathrm{HClO}_{4}$ was chosen as the optimum value for the digestion procedure. 


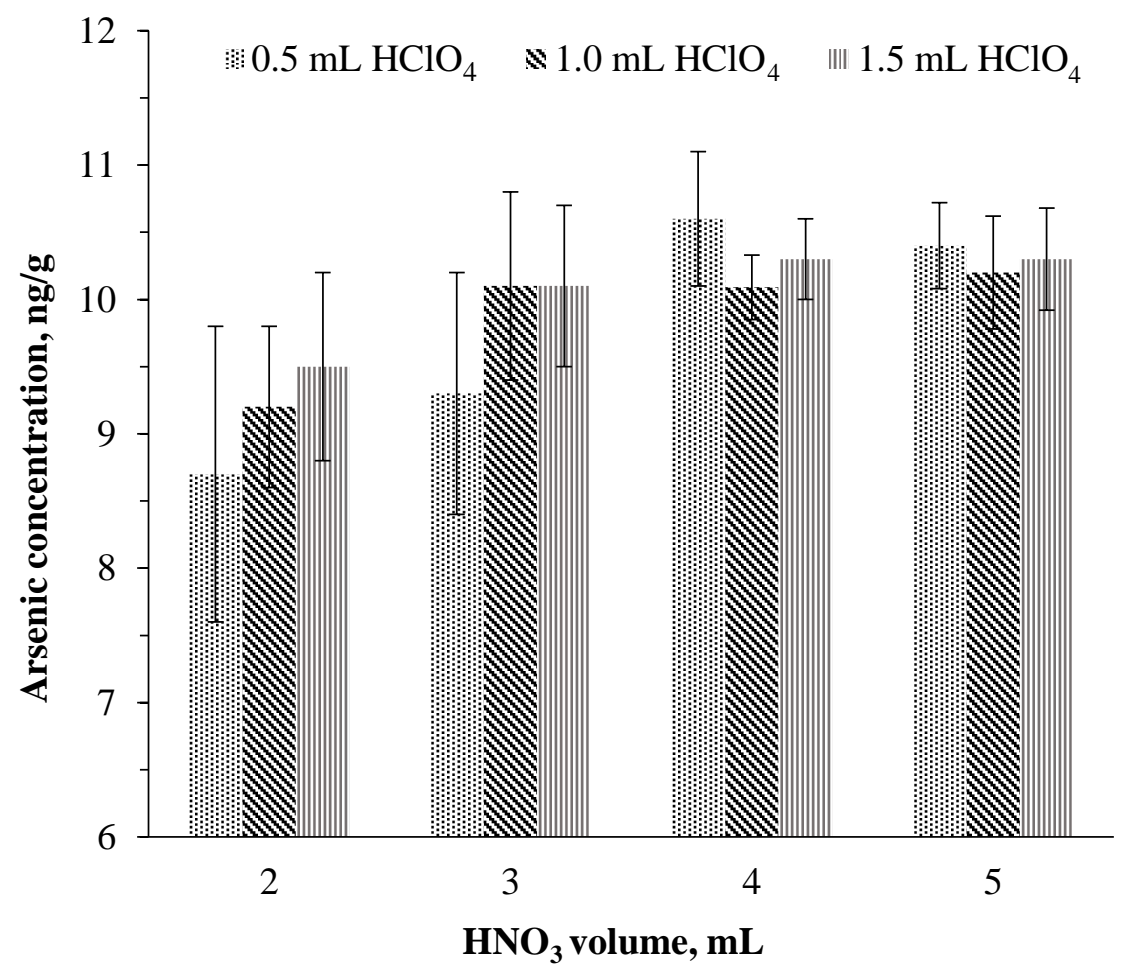

Figure 1. Optimization of $\mathrm{HNO}_{3}$ and $\mathrm{HClO}_{4}$ volume for digestion of samples, (n=3)

Since the amount of poultry and meat samples used for digestion were higher than DOLT 3 CRM; different weighed amounts $(100,300,500,700 \mathrm{mg})$ of a randomly selected poultry sample was weighed and the same digestion procedure was applied to ensure that the samples were digested properly. According to the obtained results, arsenic concentration was consentient for 100, 300, 500 and $700 \mathrm{mg}$ weighed samples (Figure 2). Therefore, it was concluded that the amount of acids and the digestion procedure was adequate to digest the samples.

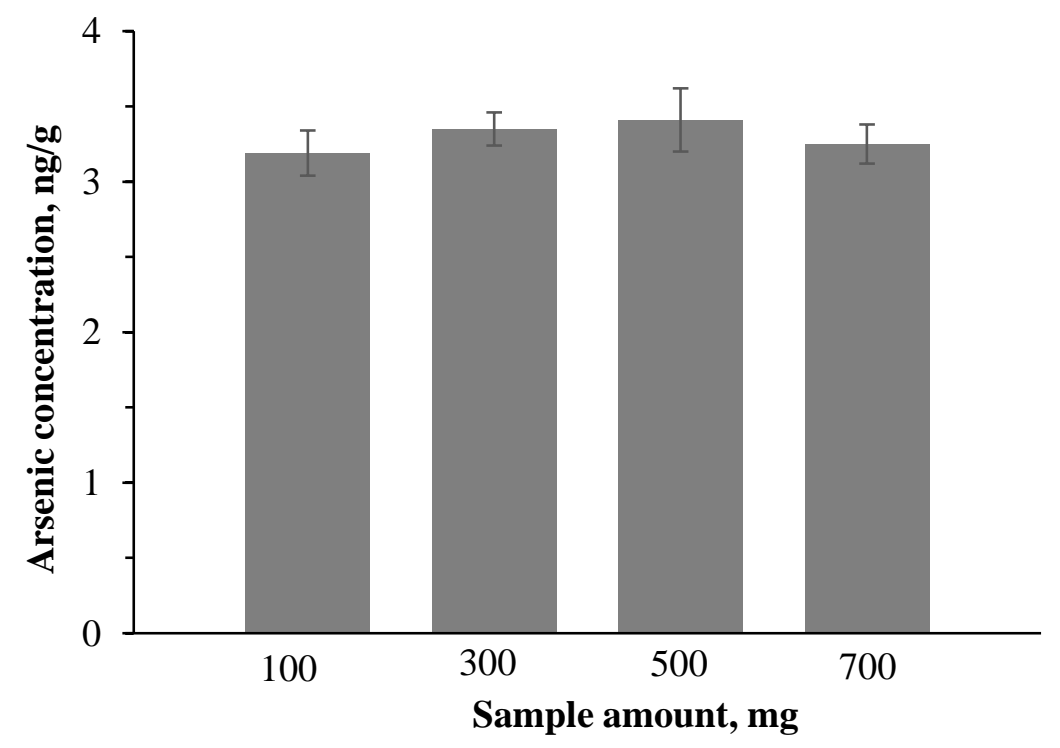

Figure 2. The effect of sampling weight amount for digestion procedure, $(n=3)$ 


\subsection{Sample Preparation and Open vessel Digestion Procedure}

The meat samples were placed in long-necked glass digestion tubes and digested in a thermostatic heating block, (Grant Instruments, United Kingdom). Each sample was homogenized and 300-600 mg was weighed from each homogenized sample and transferred into long-necked digestion tubes and $4.0 \mathrm{~mL} \mathrm{HNO}_{3}$ was added. Temperature was increased to $80^{\circ} \mathrm{C}$ and stayed constant for $15 \mathrm{~min}$., thereafter temperature was raised to $130^{\circ} \mathrm{C}$ and remained $15 \mathrm{~min}$. Then, $1.0 \mathrm{~mL} \mathrm{HClO}_{4}$ was added and heated up to $170^{\circ} \mathrm{C}$ for $15 \mathrm{~min}$. After cooling down, $0.5 \mathrm{~mL} \mathrm{H}_{2} \mathrm{SO}_{4}$ was added and the temperature raised to $230^{\circ} \mathrm{C}$. The temperature stayed constant at $230^{\circ} \mathrm{C}$ for $15 \mathrm{~min}$ then, the temperature raised to $300^{\circ} \mathrm{C}$ and stayed for 30 min thereby, $\mathrm{HNO}_{3}$ and $\mathrm{HClO}_{4}$ were evaporated. After cooling to room temperature, digested samples were diluted to $10 \mathrm{~mL}$ with ultrapure water. From this digested sample, $5 \mathrm{~mL}$ was taken and after adding $1.25 \mathrm{~mL}$ concentrated $\mathrm{HCl}$, it was diluted to $10 \mathrm{~mL}$. So that the final $\mathrm{HCl}$ and $\mathrm{H}_{2} \mathrm{SO}_{4}$ concentrations of the digested samples were $1.5 \mathrm{~mol} / \mathrm{L}$ and $0.45 \mathrm{~mol} / \mathrm{L}$, respectively. All the samples were digested in triplicate.

In order to digest DOLT 3 CRM, the same digestion procedure that was described above was applied with slight modifications such as, reducing the weighed amount $(100 \mathrm{mg})$ and increasing the dilution volume because of its high arsenic concentration.

\subsection{Analytical Performance Parameters of HG-AFS Method}

The analytical performance parameters of HG-AFS method were shown in Table 2. The method limit of detection (LOD) and limit of quantification (LOQ) values were calculated as 3.3 and 10 times the standard deviation (SD) of 10 consecutive measurements of the sample blank signal, respectively and divided by the slope of the calibration curve. The LOD and LOQ value of the method was $0.3 \mathrm{ng} / \mathrm{g}$ and $1 \mathrm{ng} / \mathrm{g}$, respectively. The repeatability of the method was determined by using the calibration standard with the lowest arsenic concentration $(25 \mathrm{pg} / \mathrm{mL})$, and in terms of RSD, repeatability was calculated less than $3 \%$.

Table 2. Analytical performance parameters of $H G-A F S$

\begin{tabular}{ll}
\hline Parameter & Value \\
\hline Dynamic range, $\mathrm{pg} / \mathrm{mL}$ & $25-5000$ \\
Calibration equation & $\mathrm{y}=8.89[\mathrm{As}]+138.4\left(\mathrm{R}^{2}=0.9996\right)$ \\
RSD, \% & $1-3$ \\
LOD, ng/g & 0.3 \\
Sampling frequency, $\mathrm{h}^{-1}$ & 50 \\
\hline
\end{tabular}

Certified reference material (DOLT 3 Dogfish Liver) was used in order to check the accuracy of HG-AFS. The CRM was digested in triplicate with the same procedure, which was described previously, and aqueous calibration standards were used to calculate the arsenic concentration. When the certified and the calculated concentrations were compared, the results were in good agreement with the certified value at $95 \%$ confidence level where the certified value was $10.2 \pm 0.5 \mathrm{mg} / \mathrm{kg}$ and the calculated value was $10.3 \pm 0.4$ $\mathrm{mg} / \mathrm{kg}$.

\subsection{Determination of Arsenic in Samples}

Arsenic concentration of 31 poultry and calf meat samples which were purchased from local stores was determined with the proposed HG-AFS method. Among the samples 11 of them was calf, 14 of them was chicken and 6 of them was turkey samples. As shown in Table 3, As concentration in calf meat is significantly higher than the poultry (chicken and turkey) samples and the arsenic concentration in turkey and chicken samples are almost the same. Amongst the published studies, determination of arsenic concentration in chicken samples obtained from Turkish market is very limited. Kaya et al. [32] evaluated seasonal variations of arsenic concentration in chicken samples and arsenic concentration in breast tissues was found 3-14 ng/g. In another study, arsenic concentration was varied in between 60-100 ng/g in various parts of chicken samples [33]. Yaman and Akdeniz determined arsenic in poultry samples and arsenic concentration was found to be $290 \pm 30 \mathrm{ng} / \mathrm{g}$ [34]. 
Table 3. Arsenic concentration levels of poultry and calf meat samples, $(n=3)$

\begin{tabular}{llll}
\hline Sample & Concentration, $\mathbf{n g} / \mathbf{g}$ & Concentration, $\mathbf{n g} / \mathbf{g}$ & Concentration, $\mathbf{n g} / \mathbf{g}$ \\
\hline & Calf & Chicken & Turkey \\
\hline 1 & $16.1 \pm 1.5$ & $2.7 \pm 0.2$ & $4.9 \pm 0.7$ \\
2 & $14.2 \pm 2.0$ & $3.5 \pm 0.3$ & $3.8 \pm 0.8$ \\
3 & $4.8 \pm 1.1$ & $2.4 \pm 0.3$ & $3.3 \pm 0.2$ \\
4 & $11.1 \pm 0.9$ & $2.4 \pm 0.2$ & $2.0 \pm 0.5$ \\
5 & $15.1 \pm 1.2$ & $1.1 \pm 0.5$ & $3.4 \pm 0.5$ \\
6 & $11.3 \pm 0.6$ & $2.3 \pm 0.6$ & \\
7 & $5.5 \pm 0.9$ & $2.9 \pm 0.1$ & \\
8 & $15.3 \pm 0.8$ & $5.6 \pm 0.7$ & \\
9 & $14.1 \pm 0.6$ & $1.5 \pm 0.6$ & \\
10 & $15.3 \pm 2.5$ & $3.7 \pm 0.6$ & \\
11 & $11.1 \pm 0.8$ & $3.7 \pm 0.4$ & \\
12 & & $3.0 \pm 0.1$ & \\
13 & & $1.4 \pm 0.2$ & \\
14 & & $3.1 \pm 0.1$ & \\
\hline
\end{tabular}

\subsection{Dietary Exposure Estimation of Arsenic}

According to the official OECD/FAO report, which includes the average consumption of meat products per person in Turkey stated that poultry and calf meat consumption is $53 \mathrm{~g}$ and $23 \mathrm{~g}$ per day, respectively [35]. Thus, the estimation of arsenic dietary intake via meat products was calculated by using the data given in OECD/FAO official report and multiplying the mean As concentration of each food by its mean consumption in Turkey. According to our results, daily intake of total arsenic via calf meat is almost two times more than via poultry meat (Table 4 ).

Table 4. Daily intake of arsenic by consumption of calf and poultry products

\begin{tabular}{lcc}
\hline Product & Consumption (g/day) & Arsenic intake (ng/day) \\
\hline Calf meat & 23 & 279 \\
Poultry meat & 53 & 155 \\
\hline
\end{tabular}

\section{RESULTS}

In this study, determination of total arsenic concentration in poultry and calf meat samples was achieved with a cost effective and an easy HG-AFS method. Since the sensitivity of HG-AFS is high, LOD value at $\mathrm{ng} / \mathrm{g}$ level can easily be achieved. Therefore, after the samples were digested, total arsenic concentration could be determined directly by appropriate dilution of the samples without using any preconcentration step. Depending on the results, the arsenic concentrations of calf meat samples were significantly higher than the poultry samples, whereas the concentrations in turkey and chicken samples were almost the same.

\section{CONFLICTS OF INTEREST}

No conflict of interest was declared by the authors.

\section{REFERENCES}

[1] Smedley, P.L. and Kinniburgh, D.G., "A review of the source, behaviour and distribution of arsenic in natural waters", Applied Geochemistry, 17(5): 517-568, (2002).

[2] Leermakers, M., Baeyens, W., De Gieter, M., Smedts, B., Meert, C., De Bisschop, H.C., Morabito, R. and Quevauviller, P., "Toxic arsenic compounds in environmental samples: Speciation and validation", TrAC Trends in Analytical Chemistry, 25(1): 1-10, (2006). 
[3] Cohen, S.M., Arnold, L.L., Beck, B.D., Lewis, A.S. and Eldan, M., "Evaluation of the carcinogenicity of inorganic arsenic", Critical Reviews in Toxicology, 43(9): 711-752, (2013).

[4] Llorente-Mirandes, T., Rubio, R. and López-Sánchez, J.F., "Inorganic Arsenic Determination in Food: A Review of Analytical Proposals and Quality Assessment Over the Last Six Years", Appl Spectrosc, 71(1): 25-69, (2017).

[5] Authority E.F.S., "Dietary exposure to inorganic arsenic in the European population", EFSA Journal, 12(3), (2014).

[6] Fisher, D.J., Yonkos, L.T. and Staver, K.W., "Environmental Concerns of Roxarsone in Broiler Poultry Feed and Litter in Maryland, USA", Environmental Science \& Technology, 49(4): 19992012, (2015).

[7] Liu, Q., Peng, H., Lu, X., Zuidhof, M.J., Li, X.F. and Le, X.C., "Arsenic Species in Chicken Breast: Temporal Variations of Metabolites, Elimination Kinetics, and Residual Concentrations", Environmental Health Perspectives, 124(8): 1174-1181, (2016).

[8] Yang, Z., Peng, H., Lu, X., Liu, Q., Huang, R., Hu, B., Kachanoski, G., Zuidhof, M.J. and Le, X.C., "Arsenic Metabolites, Including N-Acetyl-4-hydroxy-m-arsanilic Acid, in Chicken Litter from a Roxarsone-Feeding Study Involving 1600 Chickens", Environmental Science \& Technology, 50(13): 6737-6743, (2016).

[9] Barbaste, M., Medina, B. and Perez-Trujillo, J.P., "Analysis of arsenic, lead and cadmium in wines from the Canary Islands, Spain, by ICP/MS", Food Additives and Contaminants, 20(2): 141-148, (2003).

[10] Guillod-Magnin, R., Brüschweiler, B.J., Aubert, R. and Haldimann, M., "Arsenic species in rice and rice-based products consumed by toddlers in Switzerland", Food Additives and Contaminants - Part A Chemistry, Analysis, Control, Exposure and Risk Assessment: 1-15, (2018).

[11] Lee, S.G., Kim, D.H., Lee, Y.S., Cho, S.Y., Chung, M.S., Cho, M., Kang, Y., Kim, H., Kim, D. and Lee, K.W., "Monitoring of arsenic contents in domestic rice and human risk assessment for daily intake of inorganic arsenic in Korea", Journal of Food Composition and Analysis, 69: 2532, (2018).

[12] Nawab, J., Farooqi, S., Xiaoping, W., Khan, S. and Khan, A., "Levels, dietary intake, and health risk of potentially toxic metals in vegetables, fruits, and cereal crops in Pakistan", Environmental Science and Pollution Research, 25(6): 5558-5571, (2018).

[13] Nuapia, Y., Chimuka, L. and Cukrowska, E., "Assessment of heavy metals in raw food samples from open markets in two African cities", Chemosphere, 196: 339-346, (2018).

[14] Popovic, A.R., Djinovic-Stojanovic, J.M., Djordjevic, D.S., Relic, D.J., Vranic, D.V., Milijasevic, M.P. and Pezo, L.L., "Levels of toxic elements in canned fish from the Serbian markets and their health risks assessment", Journal of Food Composition and Analysis, 67: 70-76, (2018).

[15] Williams, P.N., Islam, M.R., Adomako, E.E., Raab, A., Hossain, S.A., Zhu, Y.G., Feldmann, J. and Meharg, A.A., "Increase in rice grain arsenic for regions of Bangladesh irrigating paddies with elevated arsenic in groundwaters", Environmental Science and Technology, 40(16): 49034908, (2006).

[16] Altunay, N. and Gürkan, R., "Determination of sub-ng g- 1 levels of total inorganic arsenic and selenium in foods by hydride-generation atomic absorption spectrometry after pre-concentration", 
Food Additives and Contaminants - Part A Chemistry, Analysis, Control, Exposure and Risk Assessment, 34(3): 390-403, (2017).

[17] Anawar, H.M., "Arsenic speciation in environmental samples by hydride generation and electrothermal atomic absorption spectrometry", Talanta, 88: 30-42, (2012).

[18] Khaligh, A., Mousavi, H.Z., Shirkhanloo, H. and Rashidi, A., "Speciation and determination of inorganic arsenic species in water and biological samples by ultrasound assisted-dispersive-microsolid phase extraction on carboxylated nanoporous graphene coupled with flow injection-hydride generation atomic absorption spectrometry", RSC Advances, 5(113): 93347-93359, (2015).

[19] Pistón, M., Silva, J., Pérez-Zambra, R., Dol, I. and Knochen, M., "Automated method for the determination of total arsenic and selenium in natural and drinking water by HG-AAS", Environmental Geochemistry and Health, 34(2): 273-278, (2012).

[20] Ay, U. and Henden, E., "Interferences in the quartz tube atomizer during arsenic and antimony determination by hydride generation atomic absorption spectrometry", Spectrochimica Acta Part B: Atomic Spectroscopy, 55(7): 951-958, (2000).

[21] Gundogdu, O. and Ay, U., "Development of a new method for the determination of arsenic in baby formulas by using extraction method", Fresenius Environmental Bulletin, 22(12): 35843587, (2013).

[22] Li, N., Fang, G., Zhao, L. and Wang, S., "Determination of arsenic in foods by flow injection online sorption pre-concentration with hydride generation atomic fluorescence spectrometry", Food Additives and Contaminants - Part A Chemistry, Analysis, Control, Exposure and Risk Assessment, 26(6): 839-846, (2009).

[23] Castro Grijalba, A., Fiorentini, E.F., Martinez, L.D. and Wuilloud, R.G., "A comparative evaluation of different ionic liquids for arsenic species separation and determination in wine varietals by liquid chromatography - hydride generation atomic fluorescence spectrometry", Journal of Chromatography A, 1462: 44-54, (2016).

[24] dos Santos, W.N.L., Cavalcante, D.D., Macedo, S.M., Nogueira, J.S. and da Silva, E.G.P., "Slurry Sampling and HG AFS for the Determination of Total Arsenic in Rice Samples", Food Analytical Methods, 6(4): 1128-1132, (2013).

[25] Maher, W.A., Ellwood, M.J., Krikowa, F., Raber, G. and Foster, S., "Measurement of arsenic species in environmental, biological fluids and food samples by HPLC-ICPMS and HPLC-HGAFS", Journal of Analytical Atomic Spectrometry, 30(10): 2129-2183, (2015).

[26] Saucedo-Velez, A.A., Hinojosa-Reyes, L., Villanueva-Rodriguez, M., Caballero-Quintero, A., Hernandez-Ramirez, A. and Guzman-Mar, J.L., "Speciation analysis of organoarsenic compounds in livestock feed by microwave-assisted extraction and high performance liquid chromatography coupled to atomic fluorescence spectrometry", Food Chemistry, 232: 493-500, (2017).

[27] Nachman, K. E., Baron, P.A., Raber, G., Francesconi, K.A., Navas-Acien A. and Love D.C., "Roxarsone, Inorganic Arsenic, and Other Arsenic Species in Chicken: A US-Based Market Basket Sample", Environmental Health Perspectives, 121(7): 818-824, (2013).

[28] Nigra, A. E., Nachman, K. E., Love, D. C., Grau-Perez, M. and Navas-Acien, A., "Poultry Consumption and Arsenic Exposure in the US Population", Environmental Health Perspectives, 125(3): 370-377, (2017). 
[29] Hu, Y., Zhang, W., Cheng, H. and Tao, S., "Public Health Risk of Arsenic Species in Chicken Tissues from Live Poultry Markets of Guangdong Province, China", Environmental Science \& Technology, 51(6): 3508-3517, (2017).

[30] Perelló, G., Martí-Cid, R., Llobet, J.M. and Domingo, J.L., "Effects of Various Cooking Processes on the Concentrations of Arsenic, Cadmium, Mercury, and Lead in Foods", Journal of Agricultural and Food Chemistry, 56(23): 11262-11269, (2008).

[31] Welz, B., Wolynetz, M.S. and Verlinden, M., "Interlaboratory trial on the determination of selenium in lyophilized human serum, blood and urine using hydride generation atomic absorption spectrometry", Pure and Applied Chemistry, 59(7): 927-936, (1987).

[32] Kaya, G., Karaaslan, N.M. and Yaman, M., "Seasonally variations of arsenic species in chicken meats consumed by Turkish people with HG-AAS", Fresenius Environmental Bulletin, 27(2): 645-650, (2018).

[33] Uluozlu, O.D., Tuzen, M., Mendil, D. and Soylak, M., "Assessment of trace element contents of chicken products from turkey", Journal of Hazardous Materials, 163(2-3): 982-987, (2009).

[34] Yaman, M. and Akdeniz, I., "Effects of different chemical modifiers on the determination of arsenic by electrothermal atomic absorption spectrometry and application to the poultry and plant samples", Trace Elements and Electrolytes, 23(4): 237-241, (2006).

[35] Internet: https://data.oecd.org/agroutput/meat-consumption.htm. (2020). 